\title{
Genetic Parameters for Conformation Traits in Herds that Differ in Mean Final Score and Completeness of Pedigree and Performance Data
}

\author{
N. R. Zwald, ${ }^{1}$ K. A. Weigel, ${ }^{1}$ and T. J. Lawlor, Jr. ${ }^{2}$ \\ ${ }^{1}$ Department of Dairy Science, University of Wisconsin, Madison 53706 \\ ${ }^{2}$ Holstein Association USA, Inc., Brattleboro, VT 05302
}

\section{ABSTRACT}

The objectives of this study were to assess differences in the heritability of type (conformation) traits between herds that differ in mean final score and completeness of pedigree and performance data and to estimate genetic correlations among these environments. Measurement of subjective characteristics, such as conformation traits, may be more difficult in herds with poor management conditions, and genetic evaluation of sires using data from such herds could lead to inaccurate selection decisions. Furthermore, missing pedigree data is a significant problem in many herds, and a lack of phenotypic data from maternal relatives may reduce the effectiveness of animal model evaluation systems. These hypotheses were examined using type classification scores of 1,728,836 first-parity Holstein cows (from 54,223 sires) that calved from 1993 to 2002 in 24,207 US dairy herds. These data included 480,927 records from progeny test daughters, but only 254,891 (47\%) were from dams that had valid sire identification, and only 132,953 (28\%) were from dams that had also been classified. Herds were grouped into quartiles by mean classification score, percentage of known maternal grandsires, and percentage of classified dams. Estimated heritability of final score was 0.20 in herds with mean score $<74.5,0.17$ in herds with $<25 \%$ known maternal grandsires, and 0.19 in herds with $<18 \%$ classified dams. Conversely, estimates were 0.39 in herds with mean score $>78.7,0.35$ in herds with $100 \%$ known maternal grandsires, and 0.37 in herds with $>71 \%$ classified dams. Estimated genetic correlations between quartiles ranged from 0.86 to 0.95 . Based on this study, it appears that improvements in animal identification and data collection in progeny test herds would lead to greater accuracy and stability of genetic evaluations for conformation traits in US Holstein cattle.

(Key words: progeny testing, genotype by environment interaction, conformation, type)

Abbreviation key: SET = Sire Evaluation for Type.

Received January 20, 2004.

Accepted September 2, 2004.

Corresponding author: K. A. Weigel; e-mail: kweigel@wisc.edu.

\section{INTRODUCTION}

Numerous studies have examined potential genotype by environment interactions for milk production traits, but aside from Boettcher et al. (2003), few have considered potential interactions for conformation (type) traits. Recent trends in economic merit indices have led to increased selection pressure for health and fitness traits, thereby enhancing the usefulness of correlated type traits that can be measured at a younger age. Superior breeding values for final classification score (i.e., overall conformation) also contribute vitally to the marketability of a dairy sire.

In US Holsteins, type classification data from daughters of young bulls in AI progeny test programs (i.e., "first-crop" daughters) are collected primarily through the Sire Evaluation for Type (SET) program. This program, which relies heavily on large commercial dairies, contributes approximately $45 \%$ of the data used in national genetic evaluations for conformation traits. Within the SET program, each breeding company or individual bull owner pays an employee of the Holstein Association USA, Inc. to classify all milk-recorded daughters of a given progeny test bull, along with a minimum of 9 additional herdmates or "contemporaries." On the other hand, the cost of collecting type classification data from daughters of proven AI sires whose semen has been actively marketed (i.e., "second-crop" daughters) is borne by the farmer, and these data come primarily from farms with herdbook-registered animals. Because data are typically collected from all herdbook-registered, first-parity cows, the latter program usually leads to larger contemporary groups than the SET program. In addition, cows in small "pedigree" (herdbook-registered) herds may be exposed to different management conditions and may receive more individual care, as compared with cows on large commercial dairies, and these differences may affect the accuracy of genetic evaluations for conformation traits.

Zwald and Weigel (2003) noted that the product-moment correlation between final score PTA of Holstein sires based on data from first-crop progeny-test daughters and subsequent PTA of the same sires, including additional data from second-crop daughters resulting 
Table 1 Minima and maxima for variables that were used to group herds into quartiles.

\begin{tabular}{lllll}
\hline & \multicolumn{4}{c}{ Quartile } \\
\cline { 2 - 5 } & 1 & 2 & 3 & 4 \\
\hline Mean classification score & $\geq 78.8$ & 76.6 to 78.7 & 74.5 to 76.5 & $\leq 74.4$ \\
Percentage of known maternal grandsires & $100 \%$ & 63 to $99 \%$ & 25 to $62 \%$ & $\leq 24 \%$ \\
Percentage of classified dams & $\geq 72 \%$ & 42 to $71 \%$ & 18 to $41 \%$ & $\leq 17 \%$ \\
\hline
\end{tabular}

from the retail sale of proven sire semen, was 0.86 . Although few would interpret an estimate of this magnitude as a suggestion of genotype by environment interaction, even small changes in the PTA of individual sires can have significant marketing implications. Furthermore, the mean final classification score for firstcrop daughters (74.7) was significantly lower than that of second-crop daughters (77.4) (Zwald and Weigel, 2003), and a difference of this magnitude could indicate important management or environmental differences between large commercial herds that contribute progeny test daughters and pedigree herds that provide additional data from daughters of proven sires.

The objectives of this study were 2-fold: 1 ) to quantify differences in heritability between groups of herds that differed in mean classification score and completeness of pedigree and performance data and 2) to assess the potential for genotype by environment interaction by examining genetic correlations between different types of herds. Overall, our goal was to provide information that would be useful for breeding companies that wished to identify the optimal types of herds to enroll in AI progeny testing programs.

\section{MATERIALS AND METHODS}

Conformation data from first-parity Holstein cows that were classified between January 1, 1993 and December 31, 2002 were obtained from the Holstein Association USA, Inc. Records from second and later parities could not be used because multiparous daughters of sires that "fail" progeny testing (approximately 9 bulls out of every 10 that are tested) are virtually never measured. In this study, daughters that were born before their sires reached 5 yr of age were considered "firstcrop" offspring of progeny test sires, and daughters that were born $>5$ yr after their sire were considerd as "second-crop" offspring of proven AI sires. Data collected prior to January 1, 1993 were excluded because that date corresponded to the most recent major change in the Holstein Association USA, Inc. classification program; this change featured an increase from 4 major categories to 5, as well as the inclusion of feet and legs as a separate category. Although final classification score was the main focus of the study, genetic parame- ters were also estimated for overall udder score and overall feet and legs score. After excluding records from cows with a missing or invalid calving or classification dates, 1,782,836 classification records from daughters of 54,223 sires in 24,207 herds remained for analysis. These data included 480,927 first-crop daughters of 16,844 young sires in AI progeny test programs.

Herds were grouped into quartiles based on 3 variables: mean phenotypic classification score (i.e., "final score"), percentage of classified cows whose maternal grandsires were known and had valid identification numbers, and percentage of classified cows whose dams had also been classified. All 3 variables were calculated across the entire 10-yr period from January 1, 1993, to December 31, 2002.

Genetic (co)variance components were estimated using a multiple-trait BLUP animal model via Gibb's sampling, and classification scores within each quartile were considered as separate traits. Data were analyzed separately for each of the descriptive variables (mean classification score, percentage known maternal grandsires, and percentage classified dams). The following statistical model was used:

$$
\mathbf{y}=\mathbf{X}_{1} \beta+\mathbf{X}_{2} \mathbf{H}+\mathrm{Z} \mathbf{a}+\mathbf{e}
$$

where $\mathbf{y}$ contains type classification records (overall classification scores, udder scores, or feet and legs scores) from the respective quartile groups; $\beta$ contains fixed regression coefficients corresponding to age of the cow at the time of measurement; $\mathbf{H}$ contains fixed herd by date of classification (contemporary group) effects; a contains random additive genetic effects for individual animals, distributed as multivariate normal with mean $\mathbf{0}$ and (co)variance matrix $\mathbf{A} \otimes \mathbf{G}$, where $\mathbf{A}$ is the numerator relationship matrix and $\mathbf{G}$ contains genetic (co)variances between quintiles; e contains random residuals distributed as multivariate normal with mean $\mathbf{0}$ and covariance matrix $\mathbf{I} \otimes \mathbf{R}$, where $\mathbf{R}$ is a diagonal matrix of residual variances; and $\mathbf{X}_{\mathbf{1}}, \mathbf{X}_{\mathbf{2}}$, and $\mathbf{Z}$ are corresponding incidence matrices.

Genetic (co)variance parameters for overall classification score were estimated from both "raw" (unadjusted) phenotypic scores and "adjusted" phenotypic scores, where the latter were standardized to a common 
Table 2. Mean percentages of known maternal grandsires and classified dams within each quartile for mean within-herd classification score.

\begin{tabular}{lllll}
\hline & \multicolumn{4}{c}{ Mean classification score } \\
\cline { 2 - 5 } & $\geq 78.8$ & 76.6 to 78.7 & 74.5 to 76.5 & $\leq 74.4$ \\
\cline { 2 - 5 } & 95 & 74 & 44 & 29 \\
Known maternal \\
$\begin{array}{c}\text { grandsires } \\
\text { Classified dams }\end{array}$ & 59 & 39 & 22 & 14 \\
\hline
\end{tabular}

within-herd phenotypic variance using the method described by Weigel and Lawlor (1994).

\section{RESULTS AND DISCUSSION}

Minima and maxima corresponding to individual herds within each quartile for the 3 descriptive variables are shown in Table 1. Mean overall classification scores for individual herds ranged from 63.2 to 87.8 points, indicating a broad range in the physical appearance of cattle in different herds. Within individual herds, the percentage of known maternal grandsires ranged from 0 to $100 \%$. On average, only $47 \%$ of "firstcrop" daughters had valid maternal grandsire identification. Similarly, the percentage of cows whose dams were also classified ranged from 0 to $99 \%$ for individual herds. On average, only $27 \%$ of first-crop daughters of these young AI sires were from classified dams. Missing phenotypic data for dams and other maternal relatives is a major concern, because it greatly reduces the efficiency of BLUP animal model systems for breeding value estimation.

Table 3. Mean proportion of daughters from progeny test sires (i.e., "first-crop" daughters) and proven AI sires (i.e., "second-crop" daughters) within quartiles of herds grouped by mean classification score, percentage known maternal grandsires, and percentage classified dams.

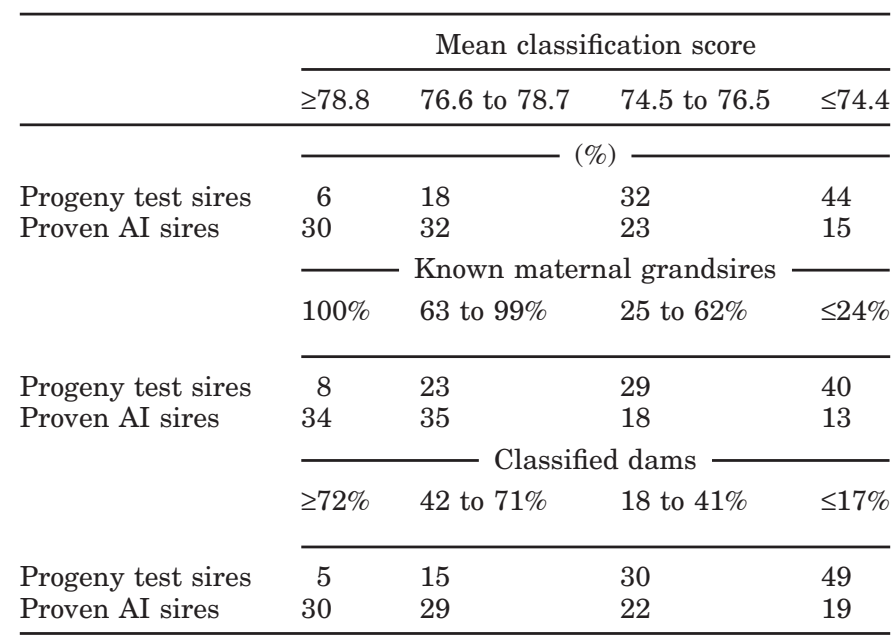

The 3 descriptive variables that were used to group herds into quartiles tended to be highly correlated with each other, as shown in Table 2 . Herds within the highest quartile for mean classification score ( $\geq 78.8$ points) had, on average, 95\% known maternal grandsires and $59 \%$ classified dams. Similarly, herds in the lowest quartile for mean classification score ( $\leq 74.5$ points) had, on average, only $29 \%$ known maternal grandsires and $14 \%$ classified dams. In particular, many cows were common to the highest quartiles for mean classification score, percentage known maternal grandsires, and percentage classified dams, because these cows resided in herds that contained primarily herdbook-registered animals.

The percentages of first-crop daughters of progeny test bulls and second-crop daughters of proven AI sires within each quartile group for each descriptive variable are shown in Table 3. It is clear that the initial genetic evaluations of most young Holstein AI sires are based largely on data from herds with low phenotypic scores that lack complete pedigree information; $44 \%$ of firstcrop daughters were in the lowest quartile for mean classification score. On the other hand, a large proportion of second-crop daughters of proven AI sires reside in herds with high phenotypic scores and relatively complete pedigree information; $62 \%$ of these cows were in the top 2 quartiles for mean classification score. Similarly, only $5 \%$ of first-crop progeny were in the top quartile for percentage of classified dams, and only $13 \%$ were in the highest quartile for percentage of known maternal grandsires. Conversely, 69 and $59 \%$ of secondcrop daughters were in the top 2 quartiles for percentage of known maternal grandsires and percentage of classified dams, respectively. This lack of pedigree and performance data can lead to inaccuracies in sire PTA, because the genetic contribution of the dam (i.e., mate) cannot be taken into consideration.

As shown in Tables 4, 5, and 6, trends in heritability estimates across quartiles were similar for all 3 descriptive variables. Heritability estimates for overall classification score were $0.39,0.33,0.24$, and 0.20 for the highest, second highest, second lowest, and lowest quartiles, as grouped by within-herd mean classification score. Corresponding estimates after adjustment for heterogeneous within-herd phenotypic variance were $0.33,0.32,0.27$, and 0.22 , respectively. The observed trend in heritability appears to indicate that classifiers can measure animals more accurately in high-scoring herds than in low-scoring herds, perhaps because they are trained using high-quality animals or because they allow more time for evaluating such animals. Overall, the heritability estimates obtained herein correspond closely to the parameter (0.29) used 
Table 4. Estimates and corresponding posterior standard deviations for heritability of final score within each quartile (on diagonal) and genetic correlations between quartiles (above diagonal) when herds were ranked by mean within-herd classification score (results after adjustment for heterogeneous within-herd phenotypic variances are shown in parentheses).

\begin{tabular}{lcccc}
\hline \multirow{2}{*}{$\begin{array}{l}\text { Mean } \\
\text { classification score }\end{array}$} & $\geq 78.8$ & 76.6 to 78.7 & 74.5 to 76.5 & $\leq 74.4$ \\
\cline { 2 - 5 }$\geq 78.8$ & $0.39 \pm 0.006$ & $0.92 \pm 0.029$ & $0.89 \pm 0.030$ & $0.86 \pm 0.025$ \\
& $(0.33 \pm 0.003)$ & $(0.91 \pm 0.026)$ & $(0.87 \pm 0.018)$ & $(0.84 \pm 0.020)$ \\
76.6 to 78.7 & & $0.33 \pm 0.005$ & $0.94 \pm 0.026$ & $0.92 \pm 0.022$ \\
& & & $(0.92 \pm 0.024)$ & $(0.91 \pm 0.025)$ \\
74.5 to 76.5 & & $0.24 \pm 0.006$ & $0.93 \pm 0.020$ \\
& & & $(0.22 \pm 0.006)$ & $(0.92 \pm 0.024)$ \\
$\leq 74.4$ & & & $0.20 \pm 0.003$ \\
& & & & $(0.22 \pm 0.004)$ \\
\hline
\end{tabular}

Table 5. Estimates and corresponding posterior standard deviations for heritability of final score within each quartile (on diagonal) and genetic correlations between quartiles (above diagonal) when herds were ranked by percentage of known maternal grandsires (results after adjustment for heterogeneous withinherd phenotypic variances are shown in parentheses).

\begin{tabular}{|c|c|c|c|c|}
\hline \multirow{2}{*}{$\begin{array}{l}\text { Percentage of } \\
\text { known maternal } \\
\text { grandsires }\end{array}$} & \multicolumn{4}{|c|}{ Percentage of known maternal grandsires } \\
\hline & $100 \%$ & 63 to $99 \%$ & 25 to $62 \%$ & $\leq 24 \%$ \\
\hline \multirow[t]{2}{*}{$100 \%$} & $0.35 \pm 0.006$ & $0.95 \pm 0.026$ & $0.90 \pm 0.025$ & $0.84 \pm 0.021$ \\
\hline & & $(0.93 \pm 0.029)$ & $(0.89 \pm 0.030)$ & $(0.84 \pm 0.020)$ \\
\hline 63 to $99 \%$ & & $0.27 \pm 0.006$ & $0.90 \pm 0.026$ & $\begin{array}{c}0.86 \pm 0.024 \\
(0.85 \pm 0.022)\end{array}$ \\
\hline \multirow[t]{2}{*}{25 to $62 \%$} & & & $0.20 \pm 0.010$ & $0.89 \pm 0.028$ \\
\hline & & & $(0.25 \pm 0.008)$ & $(0.87 \pm 0.022)$ \\
\hline \multirow[t]{2}{*}{$\leq 24 \%$} & & & & $0.17 \pm 0.003$ \\
\hline & & & & $(0.20 \pm 0.004)$ \\
\hline
\end{tabular}

Table 6. Estimates and corresponding posterior standard deviations for heritability of final score within each quartile (on diagonal) and genetic correlations between quartiles (above diagonal) when herds were ranked by percentage of classified dams (results after adjustment for heterogeneous within-herd phenotypic variances are shown in parentheses).

\begin{tabular}{|c|c|c|c|c|}
\hline \multirow{2}{*}{$\begin{array}{l}\text { Percentage of } \\
\text { classified dams }\end{array}$} & \multicolumn{4}{|c|}{ Percentage of classified dams } \\
\hline & $\geq 72 \%$ & 42 to $71 \%$ & 18 to $41 \%$ & $\leq 17 \%$ \\
\hline$\geq 72 \%$ & $\begin{array}{c}0.37 \pm 0.05 \\
(0.33 \pm 0.05)\end{array}$ & $\begin{array}{c}0.93 \pm 0.018 \\
(0.91 \pm 0.019)\end{array}$ & $\begin{array}{c}0.91 \pm 0.016 \\
(0.89 \pm 0.022)\end{array}$ & $\begin{array}{r}0.88 \pm 0.020 \\
(0.86 \pm 0.025)\end{array}$ \\
\hline 42 to $71 \%$ & & $\begin{array}{l}0.32 \pm 0.06 \\
(0.30 \pm 0.05)\end{array}$ & $\begin{array}{c}0.91 \pm 0.016 \\
(0.90 \pm 0.022)\end{array}$ & $\begin{array}{c}0.90 \pm 0.025 \\
(0.90 \pm 0.020)\end{array}$ \\
\hline 17 to $41 \%$ & & & $\begin{array}{c}0.26 \pm 0.05 \\
(0.26 \pm 0.05)\end{array}$ & $\begin{array}{c}0.94 \pm 0.029 \\
(0.91 \pm 0.024)\end{array}$ \\
\hline$\leq 16 \%$ & & & & $\begin{array}{c}0.19 \pm 0.05 \\
(0.20 \pm 0.04)\end{array}$ \\
\hline
\end{tabular}

Table 7. Estimates and corresponding posterior standard deviations for heritability of udder conformation score within each quartile (on diagonal) and genetic correlations for udder conformation score between each pair of quartiles (above diagonal) when herds were ranked by average within-herd final classification score.

\begin{tabular}{lllll}
\hline \multirow{2}{*}{$\begin{array}{l}\text { Mean } \\
\text { classification score }\end{array}$} & $\geq 78.8$ & 76.6 to 78.7 & 74.5 to 76.5 & $\leq 74.4$ \\
\cline { 2 - 5 }$\geq 78.8$ & $0.37 \pm 0.006$ & $0.90 \pm 0.028$ & $0.89 \pm 0.030$ & $0.85 \pm 0.031$ \\
76.6 to 78.7 & & $0.34 \pm 0.005$ & $0.93 \pm 0.026$ & $0.91 \pm 0.022$ \\
74.5 to 76.5 & & $0.24 \pm 0.005$ & $0.91 \pm 0.019$ \\
$\leq 74.4$ & & & $0.20 \pm 0.004$ \\
\hline
\end{tabular}


Table 8. Estimates and corresponding posterior standard deviations for heritability of feet and legs conformation score within each quartile (on diagonal) and genetic correlations for feet and legs conformation score between each pair of quartiles (above diagonal) when herds were ranked by average within-herd final classification score.

\begin{tabular}{lllll}
\hline \multirow{2}{*}{$\begin{array}{l}\text { Mean } \\
\text { classification score }\end{array}$} & $\geq 78.8$ & 76.6 to 78.7 & 74.5 to 76.5 & $\leq 74.4$ \\
\cline { 2 - 5 }$\geq 78.8$ & $0.23 \pm 0.006$ & $0.79 \pm 0.021$ & $0.78 \pm 0.028$ & $0.77 \pm 0.022$ \\
76.6 to 78.7 & & $0.16 \pm 0.004$ & $0.84 \pm 0.019$ & $0.83 \pm 0.016$ \\
74.5 to 76.5 & & $0.11 \pm 0.003$ & $0.86 \pm 0.009$ \\
$\leq 74.4$ & & & $0.09 \pm 0.005$ \\
\hline
\end{tabular}

for routine national genetic evaluation of overall conformation score (www.holsteinusa.com).

Estimated genetic correlations between the highest and lowest quartiles were 0.86 based on raw data and 0.84 based on adjusted data. These estimates were significantly $<1$, as indicated by the corresponding posterior standard deviations. It is possible that true genotype by environment interaction exists for conformation traits, such that final score in a large commercial dairy (e.g., freestalls, slatted floor) reflects different genetic characteristics than final score in a small pedigree herd (e.g., tie-stalls). On the other hand, estimates less than unity could result from nongenetic factors, such as inaccurate sire identification or evaluator bias.

Estimated heritabilities and genetic correlations for overall classification score according to quartiles for percentage of known maternal grandsires were similar to results from quartiles based on mean classification score, as shown in Table 5. Heritability estimates from raw data were $0.35,0.27,0.20$, and 0.17 for quartiles with $100 \%, 63$ to $99 \%, 25$ to $62 \%$, and $\leq 24 \%$ known maternal grandsires, respectively. Corresponding estimates from adjusted data were $0.33,0.31,0.25$, and 0.20 , respectively. The dramatic difference in heritability between the lowest and highest quartiles is understandable, because cows with unknown maternal grandsires essentially lack one-half of their pedigree information. For routine national genetic evaluation purposes, records from animals with unknown mater-

Table 9. Estimates of additive genetic and residual components of variance for overall classification score within each quartile when herds were grouped according to within-herd mean classification score.

\begin{tabular}{|c|c|c|c|c|}
\hline \multirow{2}{*}{$\begin{array}{l}\text { Mean } \\
\text { classification score }\end{array}$} & \multicolumn{2}{|c|}{ Raw data } & \multicolumn{2}{|c|}{$\begin{array}{l}\text { After heterogeneous } \\
\text { variance adjustment }\end{array}$} \\
\hline & $\sigma_{\mathrm{g}}^{2}$ & $\sigma_{\mathrm{e}}^{2}$ & $\sigma_{\mathrm{g}}^{2}$ & $\sigma_{\mathrm{e}}^{2}$ \\
\hline$\geq 78.8$ & 6.6 & 11.4 & 4.6 & 9.3 \\
\hline 76.6 to 78.7 & 7.3 & 15.3 & 4.4 & 9.7 \\
\hline 74.5 to 76.5 & 7.3 & 21.0 & 3.8 & 10.7 \\
\hline$\leq 74.4$ & 6.1 & 25.0 & 3.1 & 11.6 \\
\hline
\end{tabular}

nal grandsires receive a weight of $70 \%$, (records from animals with known maternal grandsires receive a weight of 100\%). Grouping herds by the percentage of animals with classified dams provided similar results, as shown in Table 6. The estimated genetic correlation between extreme environments, which contained herds with $\geq 72 \%$ classified dams or $\leq 17 \%$ classified dams, was 0.88 . Heritability estimates from raw data were 0.37 , $0.32,0.26$, and 0.19 , respectively, for quartiles corresponding to $\geq 72 \%, 42$ to $71 \%, 18$ to $41 \%$, and 0.20 , respectively.

Estimated heritabilities for udder conformation score, as well as estimated genetic correlations between quartiles, are shown in Table 7. The estimated heritability of overall udder score was 0.37 in herds with mean final score $\geq 78.8,0.34$ in herds with mean final score from 76.6 to $78.7,0.24$ in herds with mean final score from 74.5 to 76.5 , and 0.20 in herds with mean final score $\leq 74.4$. Heritability estimates for feet and legs score, as shown in Table 8, followed a similar pattern. Estimates were 0.23 in herds with mean final score $\geq 78.8,0.16$ in herds with mean final score from 76.6 to $78.7,0.11$ in herds with mean final score from 74.5 to 76.5 , and 0.09 in herds with mean final score $\leq 74.4$. These trends appear to indicate poorer precision of measurement in herds with poor management and/or poor genetics, and this may reduce the accuracy of genetic selection decisions.

Estimated genetic correlations between extreme environments, with mean classification score $\geq 78.8$ or mean classification score $\leq 74.4$, were 0.85 for udder score and 0.77 for feet and legs score. The latter estimate appears to contradict the results of Fatehi et al. (2003), in which reported genetic correlations were $>0.90$ between herds that were grouped according to housing system. Boettcher et al. (2003) reported higher heritability estimates for mammary system and frame and capacity in herds with conventional management ( 0.20 and 0.34 , respectively) than in herds that practiced rotational grazing ( 0.13 and 0.27 , respectively). However, the estimated heritability of feet and legs (0.17) was identical in both management systems. Esti- 
mated genetic correlations between conventional and grazing herds were 1.00 for mammary system, 0.97 for feet and legs, and 0.90 for frame and capacity.

The heterogeneous variance adjustment tended to reduce the magnitude of differences in heritability between extreme environments, largely by standardizing the error variance across environments. However, as shown in Table 9, the estimated genetic variance was reduced in each quartile as well, and this suggests that a modification to the current phenotypic adjustment procedure may be warranted.

Many studies have examined potential genotype by environment interactions for production traits (Cromie, 1999; Kearney et al., 2003; Raffrenato et al., 2003). Cromie (1999) reported a genetic correlation between extreme environments of 0.82 when herds were segmented based on milk or protein yield. Raffrenato et al. (2003) reported genetic correlations $>0.80$ between herds categorized by various criteria, with the exception of within-herd standard deviation for milk yield, which had an estimate $<0.66$ between extreme environments. Short et al. (1990) also noted that estimated heritability for milk changes according to within-herd phenotypic variance. The environment with the highest heritability $(0.28)$ also had the largest within-herd standard deviation, and the environment with the lowest heritability (0.18) had the lowest within-herd standard deviation. In contrast, Castillo-Juarez et al. (2000) found no evidence of genotype by environment interaction across environments for milk yield, somatic cell score, or conception rate.

\section{CONCLUSIONS}

Production conditions vary considerably between herds because of differences in housing, nutrition, veterinary care, climate (e.g., heat stress), and other factors. Although detailed information about the management characteristics of individual herds were unavailable in the present study, measures calculated from the data, such as mean classification score, percentage of known maternal grandsires, and percentage of classified dams, were associated with significant trends in the heritability of overall score, udder conformation, and feet and legs score. However, routine genetic evaluations for conformation traits in US Holstein cattle use a single heritability parameter that reflects the "aver- age" across all environments or production systems. Estimated genetic correlations between extreme quartiles were significantly less than unity in the present study; this is potentially concerning, because daughters of young progeny test bulls tend to reside in unfavorable environments, while daughters of proven AI sires tend to reside in favorable environments. This could lead to instability in sire rankings and could result in inaccurate or inappropriate selection decisions. Modification to the existing genetic evaluation system could alleviate some of the concerns discussed herein. For example, a "data quality rating" could be assigned to each herd, perhaps based on the descriptive variables discussed herein, or perhaps based on additional factors, such as size of contemporary group. Such modifications could be patterned after the data collection rating system that is used for routine genetic evaluation of production traits (VanRaden, 1997).

\section{REFERENCES}

Boettcher, P. J., J. Fatehi, and M. M. Schutz. 2003. Genotype $\times$ environment interactions in conventional versus pasture-based dairies in Canada. J. Dairy Sci. 86:383-389.

Castillo-Juarez, H., P. A. Oltenacu, R. W. Blake, C. E. McCulloch, and E. G. Cienfuegos-Rivas. 2000. Effect of herd environment on the genetic and phenotypic relationships among milk yield, conception rate, and somatic cell score in Holstein cattle. J. Dairy Sci. 83:807-814.

Cromie, A. R. 1999. Genotype by environment interaction for milk production traits in Holstein Friesian Dairy Cattle in Ireland. Ph.D. Thesis, The Queen's University of Belfast, UK.

Fatehi, J., A. Stella, J. J. Shannon, and P. J. Boettcher. 2003. Genetic parameters for feet and leg traits evaluated in different environments. J. Dairy Sci. 86:661-666.

Kearney, J. F., M. M. Schutz, P. Boettcher, and K. A. Weigel. 2003. Genotype by environment for grazing vs. confinement. I. Production traits. J. Dairy Sci. 87:501-509.

Raffrenato, E., R. W. Blake, P. A. Oltenacu, J. Carvalheira, and G. Licitra. 2003. Genotype by environment interaction for yield and somatic cell score with alternative environmental definitions. J. Dairy Sci. 86:2470-2479.

Short, T. R., R. W. Blake, R. L. Quaas, and L. D. Van Vleck. 1990. Heterogeneous within-herd variance. 1. Genetic parameters for first and second lactation milk yields of grade Holstein cows. J. Dairy Sci. 73:3312-3330.

VanRaden, P. M. 1997. Lactation yields and accuracies computed from test day yields and (co)variances by best prediction. J. Dairy Sci. 80:3015-3022.

Weigel, K. A., and T. J. Lawlor, Jr. 1994. Adjustment for heterogeneous variance in genetic evaluations for conformation in US Holsteins. J. Dairy Sci. 77:1691-1701.

Zwald, N. R., and K. A. Weigel. 2003. Identification of environments for AI progeny testing schemes that yield the highest heritability and correlation with second-crop evaluations for yield and type traits. J. Dairy Sci. 86(Suppl. 1):38. 